\title{
Enhancement of the Tensile and the Compression Properties for Heat- Cured Acrylic Resin Denture Base Materials
}

Mohammed Gh. Hammed ${ }^{1}$

Received 20/4/2018, Accepted 18/11/2018, Published 9/12/2018

\author{
Moaaed Motlak ${ }^{1}$
}

This work is licensed under a Creative Commons Attribution 4.0 International License.

\begin{abstract}
:
This work aims to investigate the tensile and compression strengths of heat- cured acrylic resin denture base material by adding styrene-butadiene (S- B) to polymethyl methacrylate (PMMA). The most wellknown issue in prosthodontic practice is fracture of a denture base. All samples were a blend of $(90 \%, 80 \%)$ PMMA and $(10 \%, 20 \%)$ S- B powder melted in Oxolane (Tetra hydro furan). These samples were chopped down into specimens of dimensions $100 \times 10 \times 2.5 \mathrm{~mm}$ to carry out the requirements of tensile tests. The compression strength test specimens were shaped into a cylinder with dimensions of $12.7 \mathrm{~mm}$ in diameter and $20 \mathrm{~mm}$ in length. The experimental results show a significant increase in both tensile and compression strengths when compared to control (standard) results for the preparation material.
\end{abstract}

Keywords: Acrylic resin, Compression strength, Denture base, Styrene-butadiene, Tensile strength.

\section{Introduction:}

Acrylic polymers are based on acrylic acid and its homologs and their classifications (1). Acrylic polymers as denture base materials in the form of powder was first presented by Du Pont De Nemours in the mid-twentieth century (2). Recently, materials such as porcelain, vulcanite, nitrocellulose and vinyl plastics were utilized as denture bases (3). Because of its tremendous potential for application in prosthetic dentistry, such as in denture repair, impression tray, artificial teeth, restorations, facing in crown and bridge as well as base plate, acrylic plastics have received a lot of research attention (4).

Pure polymethyl methacrylate PMMA is a colorless transparent thermoplastic (5). The polymer might be adjusted to give any translucency degree and shade. Polymerization of acrylic resins can be achieved by chemical activation, visible light or heat activation using microwave energy or heated water (6). The monomer molecules of polymers vibrate when exposed to a high- frequency electromagnetic field which leads the intermolecular collisions to produce the necessary energy for the activation process (7). A major clinical issue is the fracture of acrylic resin dentures and it is an unresolved issue in prosthodontics. The causes of denture fracture might be difficult to diagnose due to a number of variables such as denture function, handling, and processing (8).

${ }^{\mathrm{T}}$ Department of Physics, University of Anbar, Anbar, Iraq ${ }^{2}$ College of Dentistry, University of Anbar, Anbar, Iraq

*Corresponding author: moh72_gh@yahoo.com
Also, fracture has been attributed to porosity, the presence of cracks, residual monomer, or poor adaptation of the removable prosthesis to the residual ridge. Therefore, studies on the structural behavior, surface defects, and fracture initiation sites may lead to the identifying of the causes of fractures (9). In recent years, considerable attention has been paid to investigating the causes of such fractures (10). Different reviews have been made of the mechanical properties of these materials keeping in mind the end goal of enhancing dentistry (11-14).

Nowadays, polymers play a prominent role in the field of denture bases (15). The most wellknown material to construct both removable and complete dentures is polymethyl methacrylate. However, this material shows some weaknesses especially in terms of compression strength (16). The compression strength of these materials is not ideal due to recurrent fractures of denture base acrylic resins polymerized either by hot water bath or microwave energy (17). Styrene- butadiene powder dissolved in Oxolane has been added to PMMA in order to create more fracture- resistant denture base materials $(18,19)$.

\section{Tensile property}

Elasticity can be defined as the ability of a body to resist a deforming force and to return to its original size and form whenever the force is relieved (20). A well-known example is a spring that has been deformed slightly, thus the applied 
potential energy to the spring causes it to return to its original shape. The elastic region is the initial part of the stress-strain curve as shown in Fig 1. In this area the modulus is given by Hooke's law equation $\mathrm{F}=\mathrm{kx}$, where $\mathrm{k}$ is a constant factor of the spring. The point where the curve starts to digress from linearity is called the proportional limit point (21). Another vital feature of the stressstrain curve is the beginning of permanent deformation assigned as the yield point (22). Outside the limits of the yield point, the material is permanently deformed. Thus, if the stress is removed, the material may not return to its original shape. The region after the yield point is called the plastic region.

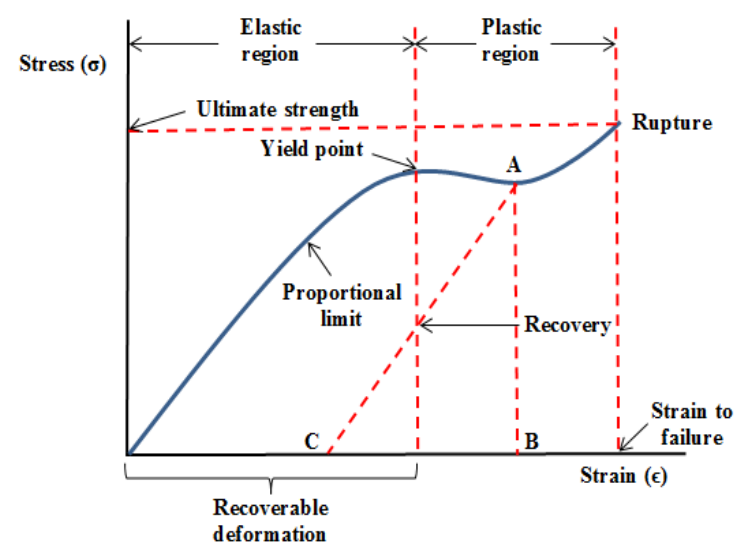

Figure 1. Stress-Strain behavior over the entire strain range for a typical polymeric material (22).

The most common type of mechanical force is tension force. One of the major mechanical properties is tensile strength, which is the capacity of a material to bear loads before breaking. Entanglement and intermolecular attractions make for high tensile strength (23). The energy levels of the molecules increase when they are pulled opposite directions. This effect generates more molecular movement (rotation, vibration, and translation). Applying more tensile force creates more disentanglement until the molecules are free to slide relative to each other. Accordingly, the more entangled the molecules, the more tensile force is required to cause them to slide (24).

\section{Compression property}

Compression force indicates the strength and stiffness of a columnar sample that is supported vertically and then pressed on its ends. The equations and symbols for stress, strain, and modulus $(\sigma, \varepsilon, E)$ developed for the tensile force are also applied to the compression force but are named compression strength, compression modulus, etc. The compression strength and modulus can be quite different from the tensile strength and modulus because of the difference in the ability of the polymer material to support a columnar load versus a pulling load. In general, compression strengths and modulus are lower than tensile values for polymers.

Compression strength is not as significant in most plastics as some of the other mechanical properties. Because of the low modulus of most plastics, the compression samples must be quite thick or be supported. The dependence of the test results on sample geometry has led to a recommendation of the testing association that compression values be used for structural studies only if the test samples are the same shape as the parts that will be in actual use.

For foam samples, the compression test is very important but is usually run under quite different conditions than these which would be used with a rigid plastic sample. The compression test for foams is therefore somewhat unique, as are many other tests associated with foam materials such as opencell content, compression set, tear-resistance, and the various cushioning tests. Test results are compression strength $(\mathrm{Pa})$, compression modules (Pa) and strain-to-failure (\%). When the yield point is exceeded in compression, a permanent deformation or compression set occurs. This compression set is important in characterizing the behavior of flexible foams (25).

\section{Materials and Methods:}

Styrene-butadiene (SB), a wide-ranging synthetic rubber, produced from the combination of styrene and butadiene, is a mixture of approximately $75 \%$ butadiene $\left(\mathrm{H}_{2} \mathrm{C}=\mathrm{CH}-\mathrm{CH}=\mathrm{CH}_{2}\right)$ and $25 \%$ styrene $\left(\mathrm{C}_{6} \mathrm{H}_{5} \mathrm{CH}=\mathrm{CH}_{2}\right)$. Styrenebutadiene powder was dissolved in Oxolane (Tetrahydrofuran), which is a colorless organic liquid with low viscosity, and its chemical formula is $\left(\mathrm{CH}_{2}\right)_{4} \mathrm{O}$. It has been classified as heterocyclic compound. All the specimens were cured by using a short curing cycle ( 90 mins. at $74{ }^{\circ} \mathrm{C}$ followed by 30 mins. at $100{ }^{\circ} \mathrm{C}$ ). There were three groups, each of which contained ten specimens. The first group specimens included poly (methyl methacrylate) and methyl methacrylate as control, 2.5:1 by weight. The second group specimens included $90 \%$ of poly (methyl methacrylate) and methyl methacrylate 2.5:1 by weight, styrene- butadiene $10 \%$ as experimental. While, the third group specimens included $80 \%$ of poly (methyl methacrylate) and methyl methacrylate $2.5: 1$ by weight, styrenebutadiene $20 \%$ as experimental. All the specimens were kept in distilled water at $37{ }^{\circ} \mathrm{C}$ for two weeks before testing. 


\section{Results and Discussion: \\ Tensile test results}

To evaluate the tensile strength of experimental and control specimens, all specimens were prepared with dimensions $(10 \times 2.5 \times 100) \mathrm{mm}$ (cross sectional area was $25 \mathrm{~mm}^{2}$ for all specimens). Specimens preparation and testing was according to ASTM specification D638M (26). All specimens were subjected to tensile testing by using Testomeric AX with a crosshead speed of $5 \mathrm{~mm} / \mathrm{min}$. The results show that the tensile strength for experimental specimens was higher than for the control specimens, as shown in Tables 1 and 2.

Table 1. Tensile test results for control, and experimental specimens of 90\% PMMA with 10\% (S- B).

\begin{tabular}{ccccccc}
\hline \multirow{2}{*}{ Samples No. } & \multicolumn{3}{c}{ Control specimens } & \multicolumn{3}{c}{ Experimental specimens } \\
\cline { 2 - 7 } & $\begin{array}{c}\text { Max. load } \\
(\mathbf{N})\end{array}$ & $\begin{array}{c}\text { Elongation \% } \\
\text { Tensile strength } \\
(\mathbf{M P a})\end{array}$ & $\begin{array}{c}\text { Max. load } \\
(\mathbf{N})\end{array}$ & $\begin{array}{c}\text { Elongation \% } \\
\text { Tensile strength } \\
(\mathbf{M P a})\end{array}$ & $\begin{array}{c}\text { (1) } \\
29.90\end{array}$ \\
2 & 480.5 & 0.805 & 20.21 & 495.9 & 0.607 & 29.98 \\
3 & 487.2 & 0.705 & 20.45 & 520.8 & 0.509 & 30.12 \\
4 & 490.3 & 0.802 & 22.13 & 580.6 & 0.701 & 30.10 \\
5 & 498.7 & 0.807 & 20.31 & 601.2 & 0.602 & 31.01 \\
6 & 502.6 & 0.806 & 19.84 & 592.3 & 0.508 & 28.84 \\
7 & 509.5 & 0.709 & 21.86 & 602.1 & 0.601 & 28.96 \\
8 & 512.4 & 0.707 & 19.82 & 585.5 & 0.609 & 30.16 \\
9 & 513.4 & 0.805 & 19.66 & 608.7 & 0.706 & 29.73 \\
10 & 521.6 & 0.706 & 21.24 & 612.4 & 0.702 & 30.64 \\
\hline
\end{tabular}

Table 2: Tensile test results for control and experimental specimens of $80 \%$ PMMA with $20 \%$ (S- B).

\begin{tabular}{ccccccc}
\hline \multirow{2}{*}{ Samples No. } & \multicolumn{3}{c}{ Control specimens } & \multicolumn{3}{c}{ Experimental specimens } \\
\cline { 2 - 7 } & $\begin{array}{c}\text { Max. load } \\
\mathbf{( N )}\end{array}$ & Elongation & $\begin{array}{c}\text { Tensile } \\
\text { strength (MPa) }\end{array}$ & $\begin{array}{c}\text { Max. load } \\
(\mathbf{N})\end{array}$ & $\begin{array}{c}\text { Elongation \% } \\
\text { Tensile } \\
\text { strength (MPa) }\end{array}$ \\
2 & 480.5 & 0.805 & 20.21 & 589.9 & 0.408 & 31.26 \\
3 & 487.2 & 0.705 & 20.45 & 590.8 & 0.507 & 32.29 \\
4 & 490.3 & 0.802 & 22.13 & 653.6 & 0.605 & 30.26 \\
5 & 498.7 & 0.807 & 20.31 & 655.5 & 0.506 & 30.91 \\
6 & 502.6 & 0.806 & 19.84 & 660.4 & 0.502 & 31.45 \\
7 & 509.5 & 0.709 & 21.86 & 661.2 & 0.508 & 29.39 \\
8 & 512.4 & 0.707 & 19.82 & 670.5 & 0.406 & 32.45 \\
9 & 513.4 & 0.805 & 19.66 & 682.7 & 0.604 & 32.19 \\
10 & 521.6 & 0.706 & 21.24 & 702.3 & 0.601 & 29.86 \\
\hline
\end{tabular}

This is because most polymer materials, especially PMMA shrink under the high tensile strength and have long molecular chains which cross-link with each other when it becomes hard. The resistance of these materials depends on the direction, regularity and cross-linkage degree of the molecular chains. External forces play an active role in the effect on cross-linkage chain strength. Applying the external load on PMMA material would affect nature and direction of cross-linkage polymer chains and that causing breaking the polymer chains. The fraction region will exhibit a breakable behavior because it has not found reinforced materials that prevent the cracks from propagation inside the specimens, and the specimens will separate into two parts as shown in Fig 2.

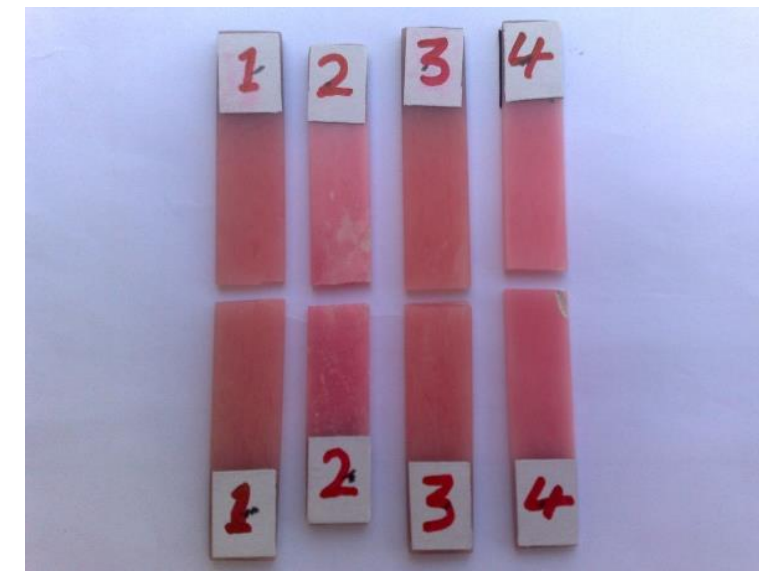

Figure 2. Fracture regions of control specimens

In the case of the experimental samples group, the results show that the elasticity of these specimens was lower than the elasticity of the control specimens, and the values of tensile strength 
increased with increasing the concentration of styrene- butadiene, as shown in Fig 3.

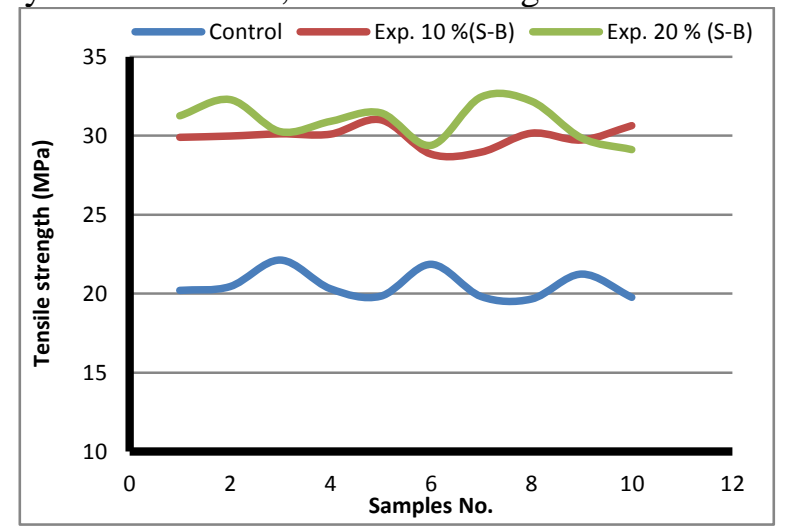

Figure 3. Tensile strength of control, and Experimental specimens with various concentrations of (S-B)

When comparing the control and experimental specimens, the applied stresses and the tensile strengths until failure for the experimental specimens were higher than for the control specimens. This is because of the good coherence strength between PMMA and S- B for experimental samples. The specimens are separated into two parts and the fracture region will brittle without undergoing any deformation, as shown in Fig 4.

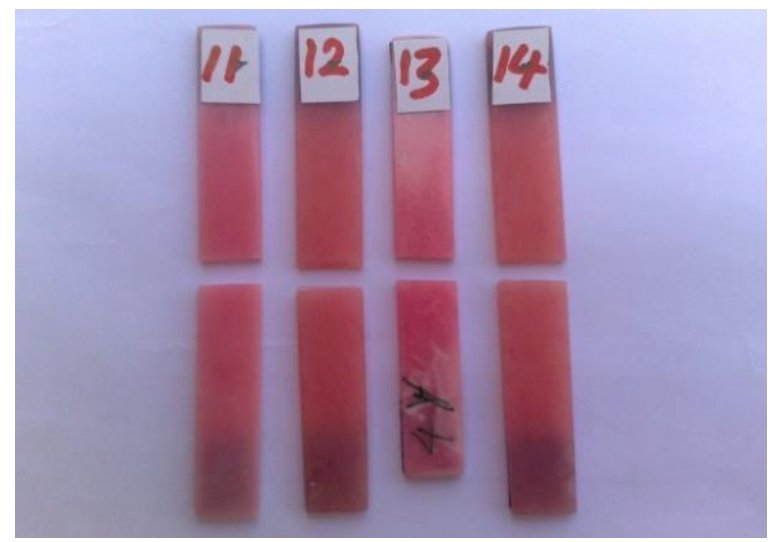

Figure 4. Fracture regions of experimental specimens

\section{Compression test results}

Head cured acrylic cylinder specimens were prepared with a diameter of $12.7 \mathrm{~mm}$ and a length of $20 \mathrm{~mm}$. The specimens were subjected to compression load by using a compression machine with a crosshead speed of $0.5 \mathrm{~mm} / \mathrm{min}$ to calculate the compression strength by dividing maximum load on the cross-sectional area, as shown in Fig 5.

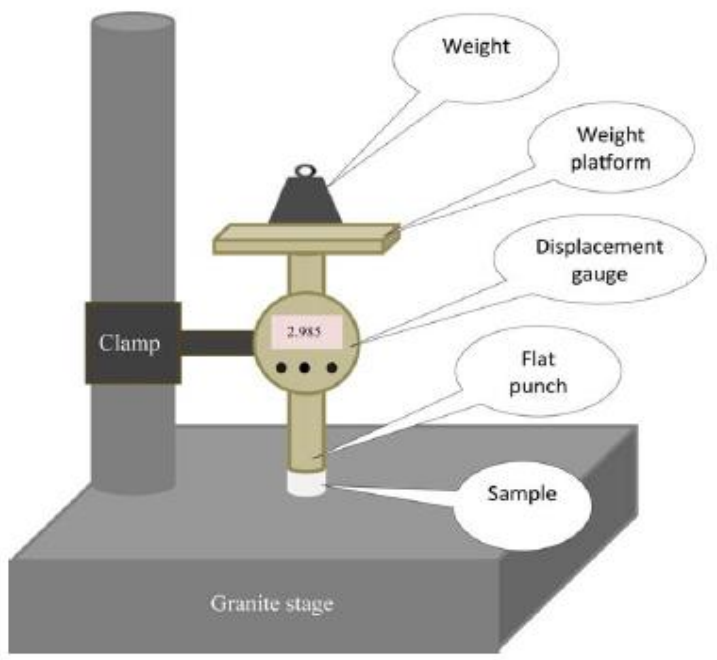

Figure 5. Schematic illustration of the compression instrument (27).

Tables 3 and 4 show that the compression strength values of the experimental specimens were higher than those of the control specimens. Because of the addition of S- B to PMMA in the experimental specimens, the $\mathrm{S}-\mathrm{B}$ effect is achieved through the formation of cross-links between the PMMA chain and the hardener. Composite materials using PMMA with S- B have better chemical resistance, mechanical strength and environmental stability than those made only from a PMMA base.

Table 3. compression test results for control and experimental specimens 90\% PMMA with 10\% (S- B).

\begin{tabular}{ccccc}
\hline & \multicolumn{2}{c}{ Control specimens } & \multicolumn{2}{c}{ Experimental specimens } \\
\cline { 2 - 5 } Samples No. & Max. load (N) & Compression strength (MPa) & Max. load (N) & Compression strength (MPa) \\
1 & 1600 & 107.62 & 2210 & 168.69 \\
2 & 1650 & 104.80 & 1980 & 175.76 \\
3 & 1700 & 102.67 & 2101 & 149.98 \\
4 & 1750 & 109.84 & 1870 & 154.85 \\
5 & 1760 & 105.45 & 1795 & 170.16 \\
6 & 1770 & 125.25 & 1996 & 171.53 \\
7 & 1800 & 106.53 & 2041 & 169.66 \\
8 & 1870 & 98.95 & 1885 & 168.83 \\
9 & 1890 & 102.96 & 2116 & 170.05 \\
10 & 1900 & 100.70 & 1998 & 150.88 \\
\hline
\end{tabular}


Table 4. compression test results for control and experimental specimens $80 \%$ PMMA with $20 \%$ (S- B).

\begin{tabular}{|c|c|c|c|c|}
\hline \multirow[b]{2}{*}{$\begin{array}{l}\text { Samples } \\
\text { No. }\end{array}$} & \multicolumn{2}{|c|}{ Control specimens } & \multicolumn{2}{|c|}{ Experimental specimens } \\
\hline & Max. load (N) & Compression strength (MPa) & Max. load (N) & $\begin{array}{c}\text { Compression strength } \\
(\mathrm{MPa})\end{array}$ \\
\hline 1 & 1600 & 107.62 & 2480 & 170.75 \\
\hline 2 & 1650 & 104.80 & 2490 & 180.64 \\
\hline 3 & 1700 & 102.67 & 2500 & 155.25 \\
\hline 4 & 1750 & 109.84 & 2530 & 178.95 \\
\hline 5 & 1760 & 105.45 & 2550 & 160.14 \\
\hline 6 & 1770 & 125.25 & 2600 & 179.85 \\
\hline 7 & 1800 & 106.53 & 2650 & 180.19 \\
\hline 8 & 1870 & 98.95 & 2680 & 186.29 \\
\hline 9 & 1890 & 102.96 & 2700 & 168.31 \\
\hline 10 & 1900 & 100.70 & 2750 & 186.64 \\
\hline
\end{tabular}

On the other hand, when comparing the control and experimental samples, the values of compression strength increase with increasing concentrations of styrene- butadiene. Also, the applied loads for the experimental samples were higher than for the control samples, as shown in Fig 6.

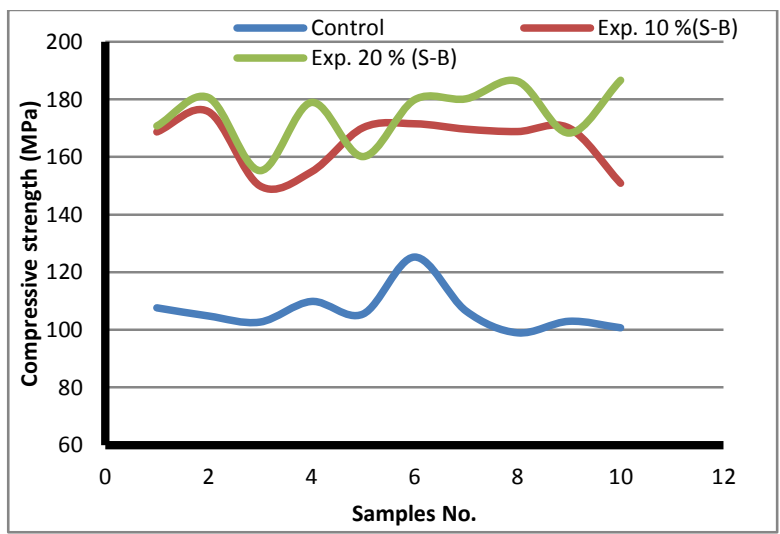

Figure 6. Compression strength of control and Experimental specimens with various concentrations of $(\mathrm{S}-\mathrm{B})$.

These are because of good strength between (PMMA) and (S- B) for experimental samples that prevent both polymer chains movement and the cracks from propagation inside samples when executing the compression test. That is, the propagation of cracks in the control specimens was greater than in the experimental specimens. During the propagation of a crack, there is a release of what is termed the elastic strain energy, some of the energy that is stored in the material as it is elastically deformed. Furthermore, during the crack extension process, a new free surface is created at the faces of a crack, which gives rise to an increase in surface energy of the system. The distribution of stresses at the crack-tip region is not altered and the crack continues to grow smoothly. As a result, the crack can advance easily through the matrix. But in the experimental specimens, the addition of S- B prevents crack propagation in the specimens and will fail at compression strength higher than control specimens.

\section{Conclusions:}

In this study, it can be concluded that the experimental specimens have tensile strength values higher than the control specimens. Both the control and experimental specimens were separated into two parts and exhibit brittle behavior when subjected to applied loads in a tensile test. The propagation of cracks in the control specimens was greater than in the experimental specimens. The compression strength values of the experimental specimens were higher than of the control specimens. Both tensile and compression strengths were enhanced by increasing the concentrations of S-B.

\section{Conflicts of Interest: None.}

\section{References:}

1. Cieplak M, Kutner W. Artificial Biosensors: How can molecular imprinting mimic biorecognition Trends Biotechnol. 2016; 34(11): 922-941.

2. Nallaswamy D. Textbook of prosthodontics. JP Medical Ltd, $2^{\text {nd }}$ ed. 2017:134.

3. Madhav G V, Raj S, Yadav N, Mudgal I, Mehta N, Tatwadiya R. Shear bond strength of acrylic teeth to acrylic denture base after different surface conditioning methods, J Contemp Dent Pract. 2013; 14(5): 892-897.

4. Sakaguchi R L, Powers J M, Craig's Restorative Dental Materials - E-Book. Elsevier Health Sciences, $13^{\text {th }}$ ed. 2012:36.

5. Parambath K Kootery, Hao Jiang. Sofiya Kolusheva, Poly(methyl methacrylate)-supported polydiacetylene films: Unique chromatic transitions and molecular sensing, ACS Appl Mater Interfaces. 2014; 6(11): 8613-8620.

6. Ivkovi N, Božovi D, Risti S. the Residual Monomer in Dental Acrylic Resin and Its Adverse Effects. Contemp Mater. 2013; 1: 84-91.

7. Gorrasi G, Sorrentino A. Mechanical milling as a 
technology to produce structural and functional bionanocomposites, Green Chem. 2015; 17(5): 26102625.

8. Pathak M, A 10-Year Retrospective Study to Evaluate Mechanical Complications Related to Implant Treatment at UT School of Dentistry The University of Texas School of Dentistry at Houston, thesis 2017.

9. Lai J, Stadler K. Investigation on the mechanisms of white etching crack (WEC) formation in rolling contact fatigue and identification of a root cause for bearing premature failure. Wear. 2016; 364: 244-256.

10. Khosla S, Jane A Cauley, Juliet Compston, Douglas P Kiel, Clifford Rosen, Addressing the crisis in the treatment of osteoporosis: a path forward. J Bone Miner Res. 2017; 32(3): 424-430.

11. Camposilvan E, Leone R, Gremillard L, Sorrentino R, Zarone F, Ferrari M, Chevalier J. Aging resistance, mechanical properties and translucency of different yttria-stabilized zirconia ceramics for monolithic dental crown applications, Dent. Mater. 2018; 34(6): 879-890.

12. Darvell B W, Materials science for dentistry. Woodhead publishing, $9^{\text {th }}$ ed. 2018:1.

13. Xuereb M, Camilleri J, Attard N J. Systematic review of current dental implant coating materials and novel coating techniques. Int J Prosthodont. 2015; 28(1).

14. Awada A, Nathanson D, Mechanical properties of resin-ceramic CAD/CAM restorative materials. $J$ Prosthet Dent. 2015; 114(4): 587-593.

15. Yadav R S, Sahare P, Prakash N, Singh S, Awasthi A. Case Report Complete Denture with Metal Base-A Case Report. 2015; 2: 205-208.

16. Leschinger T, Karsten E. Gert Peter B, Viktoria Dederer, Wolfram Friedrich Neiss, Max Joseph Scheyerer, Glass-polyalkenoate cement: An alternative material for kyphoplasty in osteoporotic vertebral compression fractures-An ex vivo study $J$ Mech Behav Biomed Mater. 2018; 83:46-51.

17. Manappallil J J. Basic dental materials. JP Medical
Ltd, $4^{\text {th }}$ ed. 2015:12.

18 Al-Fahdawi I H, Hammed M Gh, Al-Noami M M. Effect Of The Addition Of Styrene- Butadine (S-B) Dissolved In Tetra Hydro Furan (Thf) On The Some Mechanical Properties Of Heat-Cured Acrylic Resin Denture Base Materials. Egypt Dent J. 2010; 56(2): 947-952.

19. Saen-Isara T, Dechkunakorn S, Anuwongnukroh N, Srikhirin T, Tanodekaew S, Wichai W. Influence of the cross-linking agent on mechanical properties of PMMA powder with compromised particle morphology. Int Orthod. 2017; 15(2): 151-164.

20. Fletcher DA, Mullins RD. Cell mechanics and the cytoskeleton. Nature. 2010 Jan 27;463(7280):485.

21.Pelleg J. Mechanical Properties of Materials. Springer. Netherlands, $1^{\text {st }}$ ed. 2012:22.

22. Hammed M Gh. Study the tensile strength for epoxy composite reinforced with fibers and particles. J Univ anbar pure Sci. 2009; 3(2): 1-6.

23. Deanin R D. Structure-property relations in polyurethanes, in High performance biomaterials. Routledge. $1^{\text {st }}$ ed. 2017:51.

24. Yeh IC, Andzelm JW, Rutledge GC. Mechanical and structural characterization of semicrystalline polyethylene under tensile deformation by molecular dynamics simulations. Macromol. ACS 2015; Publications; 48(12): 4228-4239.

25. Simón D, de Lucas A, Rodríguez J F. Borreguero A M, Flexible polyurethane foams synthesized employing recovered polyols from glycolysis: Physical and structural properties. J Appl Polym Sci. 2017; 134(32).

26. Kimura T Nakamoto T, Microstructures and mechanical properties of A356 (AlSi7Mg0. 3) aluminum alloy fabricated by selective laser melting. Mater Des. 2016; 89: 1294-1301.

27. Wang Z, Volinsky A A, Gallant N D. Crosslinking effect on polydimethylsiloxane elastic modulus measured by custom-built compression instrument, $J$ Appl Polym Sci. 2014; 41050: 1-4.

\section{تحسين خاصيتي الثد والاتضغاط لراتنج الاكريليك المبلمر حراريا لمادة طقم الاسنان \\ مؤيد محمود مطلـ1

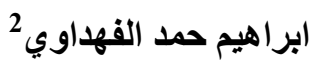 \\ محمد غازي حمد 1

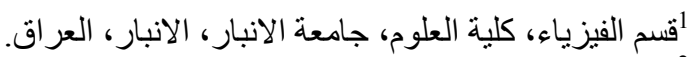

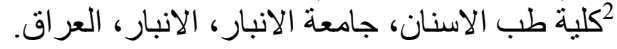

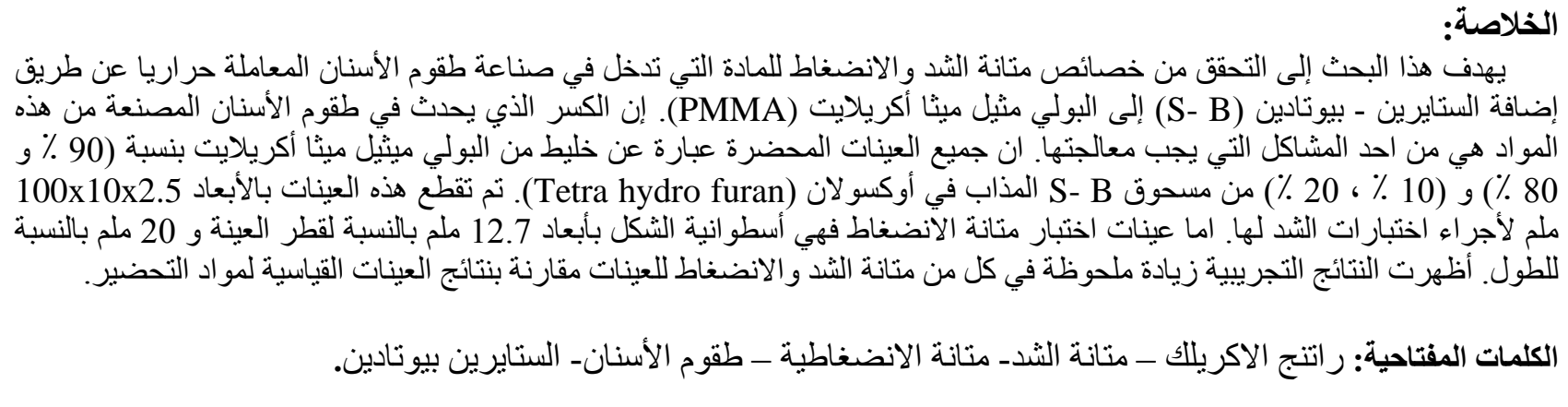

